\title{
Cost-effectiveness of computerized tomographic colonography versus colonoscopy for colorectal cancer screening
}

\author{
Steven J. Heitman, Braden J. Manns, Robert J. Hilsden, Andrew Fong, Stafford Dean, \\ Joseph Romagnuolo
}

Abstract

Background: Computerized tomographic (CT) colonography is a potential alternative to colonoscopy for colorectal cancer screening. Its main advantage, a better safety profile, may be offset by its limitations: lower sensitivity, need for colonoscopy in cases where results are positive, and expense.

Methods: We performed an economic evaluation, using decision analysis, to compare CT colonography with colonoscopy for colorectal cancer screening in patients over 50 years of age. Three-year outcomes included number of colonoscopies, perforations and adenomas removed; deaths from perforation and from colorectal cancer from missed adenomas; and direct health care costs. The expected prevalence of adenomas, test performance characteristics of CT colonography and colonoscopy, and probability of colonoscopy complications and cancer from missed adenomas were derived from the literature. Costs were determined in detail locally.

Results: Using the base-case assumptions, a strategy of CT colonography for colorectal cancer screening would cost $\$ 2.27$ million extra per 100000 patients screened; 3.78 perforation-related deaths would be avoided, but 4.11 extra deaths would occur from missed adenomas. Because screening with CT colonography would cost more and result in more deaths overall compared with colonoscopy, the latter remained the dominant strategy. Our results were sensitive to CT colonography's test performance characteristics, the malignant risk of missed adenomas, the risk of perforation and related death, the procedural costs and differences in screening adherence.

Interpretation: At present, $\mathrm{CT}$ colonography cannot be recommended as a primary means of population-based colorectal cancer screening in Canada.

CMAJ 2005;173(8):877-81

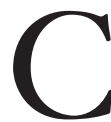

olorectal cancer is the second-leading cause of cancer death in Canada. ${ }^{1}$ Screening for colon cancer has been shown to reduce mortality ${ }^{2-4}$ and in Canada is recommended for average-risk individuals aged 50 74 years. ${ }^{5}$ Colonoscopy is highly sensitive for the identification and removal of precursor adenomatous polyps throughout the colon. Epidemiological data have suggested that removal of adenomas with colonoscopy reduces the incidence of colorectal cancer by up to $90 \% .{ }^{6}$ Compared with the success rates and costs of either no screening or fecal occult-blood testing, colonoscopy is associated with an incremental cost per life-year gained that is comparable to commonly accepted medical therapies. ${ }^{7}$

Unfortunately, the need for conscious sedation and the risk of complications (including bleeding, perforation and, rarely, death) can limit the appeal of colonoscopy for primary screening. ${ }^{8}$ These factors likely contribute to the poor compliance with current screening recommendations. In Ontario, less than $20 \%$ of eligible Canadians 50-59 years old have undergone some form of screening for this common, preventable cancer, highlighting the need for a screening procedure that is more acceptable to patients. ${ }^{9}$

CT colonography (also known as virtual colonoscopy) has been developed as a minimally invasive alternative to conventional colonoscopy. The technique still requires bowel preparation and colonic insufflation, but conscious sedation and the risks of bleeding and perforation are generally avoided. It does not, however, permit polyp removal. Well-designed prospective studies comparing CT colonography and colonoscopy involving patients with low lesion prevalence have recently been published. ${ }^{10-13}$ Although results have varied, 1 study ${ }^{11}$ reported CT colonography to have test performance characteristics equivalent to those of colonoscopy.

Previous cost-effectiveness analyses in the United States have concluded that a screening strategy employing CT colonography is more costly than one using colonoscopy. ${ }^{14,15}$ These studies are limited by outdated CT test performance characteristics ${ }^{14}$ and assumptions, such as a CT rescreening interval comparable to that of colonoscopy, ${ }^{15}$ which is possibly inappropriate. Furthermore, the results of an economic evaluation from one country are not necessarily transferable to another. ${ }^{16,17}$ To inform Canadian health policy, we performed an economic evaluation comparing the cost-effectiveness of CT colonography with that of colonoscopy for colorectal cancer screening.

\section{Methods}

Decision analysis software (DATA 3.5, TreeAge Software Inc., Williamstown, Mass.) was used to construct a model comparing CT colonography and colonoscopy for colorectal cancer screening of average-risk patients over the age of 50 years (see 
online Appendix 1, available at www.cmaj.ca/cgi/content/full/173 /8/877/DC1). A period of 3 years was chosen for the model, based on 3 considerations: the risk of cancer after a therapeutic colonoscopy (i.e., due to lesions missed at baseline) ${ }^{18}$ and the natural history of unresected large polyps $(\geq 10 \mathrm{~mm})^{19}$ are known over this period; an appropriate rescreening interval for CT colonography, although not yet established, is unlikely to be shorter than 3 years; and given that health care resources are limited in Canada, short-term economic considerations are important for health policy decision-makers.

We estimated the incremental cost per life-year gained considering the discounted life expectancy of an average 50-year-old man. In tandem with histological features, the risk of malignant transformation appears to increase with polyp size; we considered clinically significant polyps to be those larger than $5 \mathrm{~mm}$. When identified with CT colonography, they were assumed to lead to prompt referral for colonoscopy, and polypectomy if confirmed. Polyps $5 \mathrm{~mm}$ or less in size, we assumed, would not lead to further testing: their malignant potential is low, especially in the short term. The outcomes we considered included numbers of colonoscopies, perforations and adenomas removed, along with direct costs from the perspective of the health care purchaser. We calculated deaths related to perforation and from early-stage cancers arising from missed adenomas. Effectiveness was defined as a balance between death related to colonic perforations and cancers arising from missed adenomas. Colorectal cancer costs and outcomes were discounted at $3 \%$ per year.

For CT colonography, only studies using the segmental unblinding technique ${ }^{20}$ were included, whereas for colonoscopy, both segmental unblinding and back-to-back colonoscopy studies were

\section{Table 1: Baseline probabilities and ranges considered}

\begin{tabular}{|c|c|c|}
\hline Variable & $\begin{array}{l}\text { Polyp size, } \\
\text { mm }\end{array}$ & $\begin{array}{c}\text { Value } \\
\text { (range tested), \% }\end{array}$ \\
\hline $\begin{array}{l}\text { Prevalence of polyps, }{ }^{10-13} \text { including } \\
\text { adenomatous and nonadenomatous }\end{array}$ & $\begin{array}{l}6-9 \\
\geq 10\end{array}$ & $\begin{array}{l}15.5(12.2-18.9) \\
7.6(6.3-10.3)\end{array}$ \\
\hline $\begin{array}{l}\text { Probability of polyp being } \\
\text { adenomatous }^{11,13}\end{array}$ & $\begin{array}{l}6-9 \\
\geq 10\end{array}$ & $\begin{array}{l}61(40-80) \\
67(50-90)\end{array}$ \\
\hline $\begin{array}{l}\text { 3-year risk of cancer from a missed } \\
\text { adenoma }\end{array}$ & $\begin{array}{l}6-9^{23} \\
\geq 10^{19}\end{array}$ & $\begin{array}{l}0.9(0-1.5) \\
1.5(0.5-10)\end{array}$ \\
\hline Sensitivity of CT colonography ${ }^{10-13}$ & $\begin{array}{r}6-9 \\
\geq 10\end{array}$ & $\begin{array}{l}61(30-87) \\
71(55-94)\end{array}$ \\
\hline Sensitivity of colonoscopy ${ }^{10-13,21,22}$ & $\begin{array}{r}6-9 \\
\geq 10\end{array}$ & $\begin{array}{l}94(88-99) \\
96(88-100)\end{array}$ \\
\hline \multicolumn{3}{|l|}{ Specificity* } \\
\hline $\begin{array}{l}\text { CT colonography }{ }^{10-13} \\
\text { Colonoscopy }^{11-13,21,22}\end{array}$ & & $\begin{array}{c}84(80-91) \\
100\end{array}$ \\
\hline
\end{tabular}

Risk of bleeding $\dagger$

After diagnostic colonoscopy ${ }^{8} \quad 0.03(0-0.09)$

After polypectomy ${ }^{8,25,26} \quad 0.5 \quad(0-2)$

Risk of perforation ${ }^{27}$

After diagnostic colonoscopy $\quad 0.09(0.01-0.2)$

After polypectomy

$0.24(0.1-0.5)$

Risk of death from perforation ${ }^{27,33}$

$4.9(1-15)$

Survival, 5-year, after diagnosis

of early-stage colorectal cancer ${ }^{24}$

$90(85-95)$

A "true negative" was considered to be a patient with no polyps $\geq 5 \mathrm{~mm}$ in size.

tBleeding requiring hospital admission. used to assess diagnostic accuracy. A weighted average of the sizespecific sensitivities and specificities ${ }^{10-13,21,22}$ was used for the basecase estimates (for a more detailed description of our search strategy and the segmental unblinding technique, see Appendix 2, ${ }^{20-22}$ available online at www.cmaj.ca/cgi/content/full/173/8/877/DC1).

We assumed a baseline prevalence of colorectal cancer of 0 . Polyps were divided into 2 size categories: $6-9 \mathrm{~mm}$ and $\geq 10 \mathrm{~mm}$ (Table 1). The prevalence of polyps and the proportion that were adenomatous within each size category were averaged from CT colonography studies where available. ${ }^{10-13}$ The 3-year risk of cancer after an adenoma is missed by screening was estimated by natural-history data (polyps $<10 \mathrm{~mm} 0.9 \%,{ }^{23} \geq 10 \mathrm{~mm} 1.5 \%{ }^{19}$ ). Since, in the National Polyp Study, ${ }^{18}$ all cancers that developed 3 years after screening were early stage (Duke's classification A), we assumed that all cancers discovered after 3 years would have a 5year survival of $90 \% .^{24}$

Bleeding after polypectomy occurs in an estimated $2 \%$ of cases, ${ }^{8}$ with $0.5 \%$ of polypectomy patients requiring hospital admission because of it (Table 1). ${ }^{25,26} \mathrm{In}$ a recent study that summarized the literature on colonoscopy complications over the past 30 years in over 200000 diagnostic and 50000 therapeutic colonoscopies, the weighted average risk of perforation was $0.09 \%$ and $0.24 \%$, respectively. ${ }^{27}$ Mortality after colonic perforation was $4.9 \% .{ }^{27}$

The direct health care costs of colonoscopy (including costs of its therapeutic use and treatment of bleeding and perforation) and CT colonography were tabulated locally (details can be found in Appendix 3, ${ }^{11,28-31}$ available online at www.cmaj.ca/cgi/content/full /173/8/877/DC1). The lifetime cost of early-stage colorectal cancer was taken from the literature (Table 2). ${ }^{32}$

The indirect costs of colorectal cancer screening are not established and therefore were not included in the base-case analysis. They are, however, likely to be important. A patient and, frequently, a companion are required to miss work for the procedure; because of the conscious sedation, colonoscopy patients require a driver. We estimated the indirect costs of colonoscopy and CT colonography to be $\$ 213.12$ and $\$ 71.04$, respectively (as described in online Appendix 3), and considered them in our sensitivity analyses.

We subjected each of the variables modelled to sensitivity analyses over plausible ranges to assess the robustness of our conclusions (Table 1, Table 2). One potential advantage of CT colonography is to enhance the uptake of population-based colorectal cancer screening; because the available data were sparse, we modelled a wide range of increased screening adherence $(0-50 \%$, in absolute terms) for CT colonography over colonoscopy. Although adherence rates were explored in the sensitivity analysis, the base case assumed no difference in screening adherence.

\section{Table 2: Cost estimates and ranges considered}

\begin{tabular}{lcc}
\hline Variable & \multicolumn{2}{c}{ Mean cost* (range), \$ } \\
\hline Colonoscopy (diagnostic) & 546.64 & $(200-1200)$ \\
Colonoscopy with polypectomy & 667.66 & $(200-1200)$ \\
CT colonography & 445 & $(200-795)$ \\
Admission after colonoscopy & & \\
$\quad$ Because of bleeding & 3067 & $(400-25000)$ \\
$\quad$ Because of perforation & 29982 & $(2000-125000)$ \\
Predicted lifetime costs ${ }^{32}$ of & & \\
localized colorectal cancer & 22828 & \\
\hline
\end{tabular}

*Costs for overhead were local estimations unless referenced otherwise. †With or without polypectomy. 


\section{Results}

According to the base-case estimates, a strategy of CT colonography for colorectal cancer screening would cost \$2.27 million more than colonoscopy per 100000 patients screened. Colonoscopy remained the less expensive strategy until the cost of CT colonography fell below $\$ 422$. In a 100000 -patient cohort, the use of CT colonography would avoid 72800 colonoscopies, 77 perforations and almost 4 perforation-related deaths; however, an additional 3470 small and 1420 large adenomas would be missed, leading to just over 4 additional cancer-related deaths. Therefore, use of CT colonography would cost $\$ 2.27$ million extra and result in 0.33 extra deaths per 100000 patients screened, compared with colonoscopy (Table 3). As such, colonoscopy is both less expensive and more effective (i.e., dominant).

Our key sensitivity analyses are summarized in Table 4. Increasing the test performance of CT colonography to that reported by Pickhardt and colleagues ${ }^{11}$ (best-case scenario) resulted in an incremental cost per life gained of $\$ 4.11$ million or \$220 000 per life-year gained. Decreasing its test performance to that reported by Cotton and associates $^{12}$ (worst-case scenario) yielded a cost savings of $\$ 4.51$ million for the CT colonography strategy, which resulted from the reduced number of colonoscopies performed. However, this was accompanied by 2.27 extra cancer deaths compared with the colonoscopy strategy.

Our results were also sensitive to the estimated risk of cancer from missed adenomas and the risk of colonoscopyassociated perforation and death. Colonoscopy was no longer dominant when we decreased the cancer risk of a missed adenoma 6-9 $\mathrm{mm}$ in size to 0; CT colonography then had an incremental cost per life-year gained of $\$ 42$ 900. When we increased the risk of perforation from colonoscopy to $0.2 \%$, CT colonography became an attractive alternative, with a cost per life-year gained of $\$ 18200$. Increasing the risk of death from colonoscopic perforation

Table 3: Numbers of procedures and complications per 100000 people screened for colon cancer, and costs thereof

\begin{tabular}{lccc}
\hline & \multicolumn{2}{c}{ Cancer screening strategy } & \\
\cline { 2 - 3 } Variable & Colonoscopy & CT colonography & Difference \\
\hline Colonoscopies performed & 100000 & 27200 & 72800 \\
Perforations & 123 & 46 & 77 \\
Small adenomas removed & 8890 & 5420 & 3470 \\
Large adenomas removed & 4890 & 3470 & 1420 \\
\hline $\begin{array}{l}\text { Deaths } \\
\quad \text { Perforation-related }\end{array}$ & 6.03 & 2.25 & \\
$\quad$ Cancer-related, from & & & 3.78 \\
$\quad$ missed adenomas* & 0.64 & 4.75 & -4.11 \\
Total deaths & 6.67 & 7.00 & -0.33 \\
\hline Cost, \$millions & 61.5 & 63.8 & -2.27
\end{tabular}

Note: All figures are rounded to 3 significant digits.

*Deaths from colon cancer were discounted at 3\% per year. to $14 \%^{33}$ generated a cost per life-year gained of $\$ 2130$ for CT colonography.

Including an estimate of indirect costs also influenced our results, with CT colonography saving $\$ 6.15$ million, but at a cost of 0.33 extra deaths. Furthermore, increasing the absolute colorectal cancer screening penetration with CT colonography to a level 50\% higher than colonoscopy, in absolute terms, resulted in the CT strategy having fewer deaths, but at an incremental cost per life-year gained of over $\$ 700000$.

\section{Interpretation}

CT colonography has been developed as a less invasive alternative to colonoscopy to decrease perforation-related morbidity and mortality and potentially to increase population adherence with colorectal cancer screening. However, we demonstrate that primary screening with CT colonography is more expensive and leads to more overall deaths than colonoscopy. Our conclusions are sensitive to CT colonography's test performance characteristics, the malignancy risk of missed adenomas, the perforation risk and perforation-

Table 4: Summary of key sensitivity analyses showing deaths per 100000 screened and incremental cost-effectiveness ratios from the perspective of CT colonography versus colonoscopy

\begin{tabular}{|c|c|c|c|}
\hline Variable & $\begin{array}{c}\text { Deaths } \\
\text { avoided, } \\
\text { from } \\
\text { perforation }\end{array}$ & $\begin{array}{l}\text { Additional } \\
\text { deaths, } \\
\text { from missed } \\
\text { adenomas }\end{array}$ & $\begin{array}{c}\text { Incremental } \\
\text { cost per } \\
\text { life-year } \\
\text { gained, }{ }^{*} \$\end{array}$ \\
\hline Base case & 3.78 & 4.11 & $\mathrm{NA}+$ \\
\hline \multicolumn{4}{|l|}{$\begin{array}{l}\text { Test performance (from } \\
\text { the literature) }\end{array}$} \\
\hline Best: sens $94 \%$, spec $80 \%{ }^{11}$ & 2.99 & 1.16 & 220000 \\
\hline Worst: sens $55 \%$, $\ddagger$ spec $91 \%{ }^{12}$ & 4.70 & 6.97 & $(106000)$ \\
\hline \multicolumn{4}{|l|}{$\begin{array}{l}\text { 3-year cancer risk from } \\
\text { a missed polyp }\end{array}$} \\
\hline $6-9 \mathrm{~mm} \mathrm{0} \%, \geq 10 \mathrm{~mm} \mathrm{1.5 \%}$ & 3.78 & 1.67 & 42900 \\
\hline $6-9 \mathrm{~mm} 0.9 \%, \geq 10 \mathrm{~mm} \mathrm{10 \%}$ & 3.78 & 13.6 & $\mathrm{NA}+$ \\
\hline \multicolumn{4}{|l|}{ Perforation risk from colonoscopy } \\
\hline $0.05 \%$ & 2.55 & 4.11 & NA† \\
\hline $0.2 \%$ & 7.30 & 4.11 & 2130 \\
\hline \multicolumn{4}{|l|}{ Risk of death from perforation } \\
\hline $1 \%$ & 0.77 & 4.11 & $\mathrm{NA}+$ \\
\hline $14 \%{ }^{33}$ & 10.8 & 4.11 & 18200 \\
\hline Indirect cost estimates included & 3.78 & 4.11 & $(956000)$ \\
\hline \multicolumn{4}{|l|}{$\begin{array}{l}\text { Absolute improvement in } \\
\text { screening adherence }\end{array}$} \\
\hline $10 \%$ & 3.23 & 3.02 & 1860000 \\
\hline $25 \%$ & 2.55 & 1.71 & 887000 \\
\hline $50 \%$ & 1.76 & 0.15 & 711000 \\
\hline
\end{tabular}


related mortality estimates for colonoscopy, the procedural costs, and differences in screening adherence.

It is difficult to know what the test performance characteristics of CT colonography will ultimately be in routine clinical practice. However, even if they rival those of colonoscopy, we have shown that the cost of a CT colonography strategy prohibits recommending it as a primary method for colorectal cancer screening. Even in the best-case scenario, the cost per life-year gained was unattractive by conventional standards. ${ }^{34,35}$ It should be noted that Pickhardt and colleagues $^{11}$ used a primary 3 -dimensional approach for the detection of polyps rather than a primary 2-dimensional approach with 3-D reconstruction for problem-solving. Although this enhanced technology may increase polyp detection rates, it may also raise the cost of CT. The higher performance of this technology also needs to be confirmed by others.

Our results remained robust when plausible changes in the malignant potential of adenomas missed with CT colonography were considered. Although the incremental cost per life-year gained was $\$ 42900$ when the risk of a missed 6-9 mm adenoma was 0 , this is unlikely to be realistic. In fact, the real malignant risk of missed adenomas may be higher than we modelled, given that the natural-history studies cited contained a mixture of hyperplastic (no malignant potential) and adenomatous polyps. Furthermore, the risk of a missed adenoma $10 \mathrm{~mm}$ or more in size may be much higher than the $1.5 \%$ risk suggested by Stryker and coworkers. ${ }^{19}$ In the 3 -year surveillance arm $(n=428)$ of the National Polyp Study, 2 cancers within large adenomas and 12 additional advanced nonmalignant adenomas of $10 \mathrm{~mm}$ or more were found at 3 years of follow-up. ${ }^{18}$ If we assume that these 14 large adenomas were present and missed at the baseline exam, which is a reasonable assumption, the 3year malignant risk of a missed large adenoma may be as high as 2 in 14 , or $14 \%$.

Although a 1-in-1000 risk of perforation from diagnostic colonoscopy is generally accepted ${ }^{36}$ the risk may be significantly lower, especially when performed by trained gastroenterologists in an otherwise healthy outpatient screening population. ${ }^{27,37,38}$ In a large prospective study involving healthy outpatients, ${ }^{37}$ the perforation rate was $0.005 \%$ for diagnostic and $0.06 \%$ for therapeutic colonoscopy. In contrast, the risk of complications may be higher in centres with less experienced endoscopists. ${ }^{37} \mathrm{We}$ demonstrated that substantially increasing the risk of perforation or the risk of death from perforation resulted in a reasonable incremental cost-effectiveness ratio for CT colonography. Therefore, the choice of screening strategy in a given institution may depend on a balance between the availability and local quality of CT colonography and the experience and complication rates of available endoscopists and surgeons.

Including an estimate of indirect costs from predicted lost wages was shown to be important in our sensitivity analysis. Further research is needed to determine the actual indirect costs associated with colorectal cancer screening.

Lastly, using CT colonography to screen for colorectal cancer offers the potential to enhance screening adherence. Data in this area are lacking, however. Some studies have reported increased patient satisfaction with CT colonography over colonoscopy ${ }^{11,39}$ but also increased overall discomfort with CT colonography. ${ }^{11,40}$ A recent community-based study ${ }^{41}$ in which CT colonography was offered to nearly 1500 asymptomatic screening candidates had a participation rate of only $28 \%$. Therefore, even if CT colonography can increase participation for colorectal cancer screening, the overall impact might be small. Furthermore, we have shown that the cost per life-year gained remains excessive even with a large increase in screening adherence.

Our study has limitations. First, the 3-year period may be considered by some to be a limitation of our study design; but we feel, as outlined in the methods section, that key data are unavailable to permit a longer time horizon without increasing the degree of speculation and amplification of errors over time. Furthermore, the short-term cost of adopting CT colonography is an important consideration for health policy decision-makers. Second, we assumed that all cancers arising from missed adenomas would be early-stage and identified and promptly treated at the 3year mark. This represents an ideal scenario for the strategy with the higher miss rate (CT colonography). Many early cancers are asymptomatic and can progress in stage before being diagnosed, if the next screening is delayed. Third, only polyps larger than $5 \mathrm{~mm}$ were considered clinically significant. However, it is possible that, in practice, polyps $5 \mathrm{~mm}$ or smaller identified by means of CT colonography would not be ignored, leading to a colonoscopy referral or a repeat CT colonography within a shorter time interval. Both would increase the cost of a CT colonography strategy. Finally, we did not incorporate a measure of quality of life (e.g., health utility, a measure of overall quality of life ranging from 0 to 1 ) into the model, because the data are either limited or do not yet exist. Their incorporation would be highly unlikely to change our overall conclusions, however.

In conclusion, CT colonography does not appear to be cost-effective for primary colorectal cancer screening in Canada. Although perforation-related mortality can be reduced, this is counterbalanced by excess cancer-related deaths from missed adenomas. Even if the test performance characteristics of CT colonography could eventually rival those of colonoscopy, the current cost of a screening strategy involving CT colonography far exceeds what most would consider good value for health care money. CT colonography has a potential role in centres where the risks of colonoscopy are high or in patient populations with high operative mortality. Finally, given that the results of our analysis appeared sensitive to the inclusion of indirect cost estimates, further research into determining the actual indirect costs associated with colorectal cancer screening is warranted. 
This article has been peer reviewed.

From the Departments of Medicine (Heitman, Manns, Hilsden, Romagnuolo) and Community Health Sciences (Manns, Hilsden, Fong, Dean, Romagnuolo), University of Calgary, Calgary, Alta., and the Department of Medicine, Medical University of South Carolina, Charleston, SC (Romagnuolo)

\section{Competing interests: None declared.}

Contributors: Steven Heitman and Joseph Romagnuolo conceived the study, performed the literature searches and designed the model. Braden Manns and Robert Hilsden had important input into the costing methodology. Andrew Fong and Stafford Dean were involved in the gathering, analysis and tabulation of the local costing data. All authors either drafted the manuscript or revised it critically, and all approved the final version that was submitted.

Acknowledgements: We thank Peter Cotton and Benoit Pineau for agreeing to serve as content experts for the identification of relevant CT colonography and colonoscopy performance studies. We also thank the Alberta Heritage Foundation for Medical Research for funding Joseph Romagnuolo, Braden Manns and Robert Hilsden during this analysis.

\section{References}

1. National Cancer Institute of Canada. Canadian cancer statistics. Toronto: the Institute; 2003. p. 26

2. Mandel JS, Bond JH, Church TR, Snover DC, Bradley GM, Schuman LM, et al. Reducing mortality from colorectal cancer by screening for fecal occult blood. Minnesota Colon Cancer Control Study. N Engl 7 Med 1993;328:1365-71.

3. Kronborg O, Fenger C, Olsen J, Jorgensen OD, Sondergaard O. Randomised study of screening for colorectal cancer with faecal-occult-blood test. Lancet 1996;348:1467-71.

4. Hardcastle JD, Chamberlain JO, Robinson MH, Moss SM, Amar SS, Balfour TW, et al. Randomised controlled trial of faecal-occult-blood screening for colorectal cancer. Lancet 1996;348:1472-7.

5. Leddin D, Hunt R, Champion M, Cockeram A, Flook N, Gould M, et al Canadian Association of Gastroenterology; Canadian Digestive Health Foundation. Canadian Association of Gastroenterology and the Canadian Digestive Health Foundation: Guidelines on colon cancer screening. Can 7 Gastroenterol 2004;18:93-9.

6. Winawer SJ, Zauber AG, Ho MN, O'Brien MJ, Gottlieb LS, Sternberg SS et al; the National Polyp Study Workgroup. Prevention of colorectal cancer by colonoscopic polypectomy. N Engl 7 Med 1993;329:1977-81.

7. Sonnenberg A, Delco F, Inadomi JM. Cost-effectiveness of colonoscopy in screening for colorectal cancer. Ann Intern Med 2000;133:573-84.

8. Kavic SM, Basson MD. Complications of endoscopy. Am 7 Surg 2001;181:319-32

9. Rabeneck L, Paszat LF. A population-based estimate of the extent of colorectal cancer screening in Ontario. Am 7 Gastroenterol 2004;99:1141-4.

10. Pineau BC, Paskett ED, Chen GJ, Espeland MA, Phillips K, Han JP, et al. Virtual colonoscopy using oral contrast compared with colonoscopy for the detection of patients with colorectal polyps. Gastroenterology 2003;125:304-10.

11. Pickhardt PJ, Choi JR, Hwang I, Butler JA, Puckett ML, Heldebrandt HA, et al. Computed tomographic virtual colonoscopy to screen for colorectal neoplasia in asymptomatic adults. N Engl 7 Med 2003;349:2191-200.

12. Cotton PB, Durkalski VL, Peneau BC, Palesch YY, Mauldin PD, Hoffman B, et al. Computed tomographic colonography (virtual colonoscopy): a multicenter comparison with standard colonoscopy for detection of colorectal neoplasia. 7AMA 2004;291:1713-9

13. Rockey DC, Paulson E, Niedzwiecki D, Davis W, Bosworth HB, Sanders L, et al. Analysis of air contrast barium enema, computed tomographic colonography, and colonoscopy: prospective comparison. Lancet 2005;365:305-11.

14. Sonnenberg A, Delco F, Bauerfeind P. Is virtual colonoscopy a cost-effective option to screen for colorectal cancer? Am 7 Gastroenterol 1999;94:2268-74.

15. Ladabaum U, Song K, Fendrick AM. Colorectal neoplasia screening with virtual colonoscopy: when, at what cost, and with what national impact? Clin Gastroenterol Hepatol 2004;2:554-63.

16. O'Brien BJ, Heyland D, Richardson WS, Levine M, Drummond MF; Evidence-Based Medicine Working Group. Users' guides to the medical literature. XIII. How to use an article on economic analysis of clinical practice. B. What are the results and will they help me in caring for my patients? 7AMA 1997;277:1802-6.

17. Mason J. The generalisability of pharmacoeconomic studies. Pharmacoeconomics $1997 ; 11: 503-14$.

18. Winawer SJ, Zauber AG, O’Brien MJ, Ho MN, Gottlieb L, Sternberg SS, et al; the National Polyp Study Workgroup. Randomized comparison of surveillance intervals after colonoscopic removal of newly diagnosed adenomatous polyps. N Engl 7 Med 1993;328:901-6.

19. Stryker SJ, Wolff BG, Culp CE, Libbe SD, Ilstrup DM, MacCarty RL. Natural history of untreated colonic polyps. Gastroenterology 1987;93:1009-13

20. Pineau BC, Paskett ED, Chen GJ, Durkalski VL, Espeland MA, Vining DJ Validation of virtual colonoscopy in the detection of colorectal polyps and masses: rationale for proper study design. Int 7 Gastrointest Cancer 2001;30:133-40.

21. Hixson LJ, Fennerty MB, Sampliner RE, McGee D, Garewal H. Prospective study of the frequency and size distribution of polyps missed by colonoscopy. 7 Natl Cancer Inst 1990;82:1769-72.

22. Rex DK, Cutler CS, Lemmel GT, Rahmani EY, Clark DW, Helper DJ, et al. Colonoscopic miss rates of adenomas determined by back-to-back colonoscopies. Gastroenterology 1997;112:24-8.

23. Hofstad B, Vatn MH, Andersen SN, Huitfeldt HS, Rognum T, Larsen S, et al. Growth of colorectal polyps: redetection and evaluation of unresected polyps for a period of three years. Gut 1996;39:449-56.

24. Weir HK, Thun MJ, Hankey BF, Ries LAG, Howe HL, Wingo PA, et al. Annual report to the nation on the status of cancer, 1975-2000, featuring the uses of surveillance data for cancer prevention and control. 7 Natl Cancer Inst 2003;95:1276-99.

25. Rosen L, Bub DS, Reed JF III, Nastasee SA. Hemorrhage following colonoscopic polypectomy. Dis Colon Rectum 1993;36:1126-31.

26. Waye JD, Lewis BS, Yessayan S. Colonoscopy: a prospective report of complications. 7 Clin Gastroenterol 1992;15:347-51.

27. Misra T, Lalor E, Fedorak RN. Endoscopic perforation rates at a Canadian university teaching hospital. Can 7 Gastroenterol 2004;18:221-6.

28. Manns BJ, Lee H, Doig CJ, Johnson D, Donaldson C. An economic evaluation of activated protein $\mathrm{C}$ treatment for severe sepsis. N Engl 7 Med 2002; 347:993-1000.

29. McKillop I. A research project to examine the costing methodologies recommended in the MIS guidelines. Ottawa: Canadian Institute for Health Information; 1995. pp. 155.

30. Gluecker TM, Johnson CD, Wilson LA, MacCarty RL, Welch TJ, Vanness DJ, et al. Extracolonic findings at CT colonography: evaluation of prevalence and cost in a screening population. Gastroenterology 2003;124:911-6.

31. Jacob-Tacken KH, Koopmanschap MA, Meerding WJ, Severens JL. Correcting for compensating mechanisms related to productivity costs in economic evaluations of health care programmes. Health Econ 2005;14:435-43.

32. Maroun J, Ng E, Berthelot JM, Le Petit C, Dahrouge S, Flanagan WM, et al Lifetime costs of colon and rectal cancer management in Canada. Chronic Dis Can 2003;24:91-101.

33. Garbay JR, Suc B, Rotman N, Fourtanier G, Escat J. Multicentre study of surgical complications of colonoscopy. Br 7 Surg 1996;83:42-4.

34. Laupacis A, Feeny D, Detsky AS, Tugwell PX. How attractive does a new technology have to be to warrant adoption and utilization? Tentative guidelines for using clinical and economic evaluations. CMA7 1992;146:473-81.

35. Gold R, Siegel JE, Russell LB, Weinstein MC, editors. Cost-effectiveness in bealth and medicine. New York: Oxford University Press; 1996.

36. Winawer S, Fletcher R, Rex D, Bond J, Burt R, Ferrucci J, et al.; Gastrointestinal Consortium Panel. Colorectal cancer screening and surveillance: clinical guidelines and rationale - update based on new evidence. Gastroenterology 2003;124:544-60.

37. Sieg A, Hachmoeller-Eisenbach U, Eisenbach T. Prospective evaluation of complications in outpatient GI endoscopy: a survey among German gastroenterologists. Gastrointest Endosc 2001;53:620-7.

38. Nelson DB, McQuaid KR, Bond JH, Lieberman DA, Weiss DG, Johnston TK. Procedural success and complications of large-scale screening colonoscopy. Gastrointest Endosc 2002;55:307-14.

39. Angtuaco TL, Banaad-Omiotek GD, Howden CW. Differing attitudes toward virtual and conventional colonoscopy for colorectal cancer screening: surveys among primary care physicians and potential patients. Am 7 Gastroenterol 2001;96:887-93.

40. Akerkar GA, Yee J, Hung R, McQuaid K. Patient experience and preferences toward colon cancer screening: a comparison of virtual colonoscopy and conventional colonoscopy. Gastrointest Endosc 2001;54:310-5

41. Edwards JT, Mendelson RM, Fritschi L, Foster NM, Wood C, Murray D, et al. Colorectal neoplasia screening with CT colonography in average-risk asymptomatic subjects: community-based study. Radiology 2004;230:459-64.

Correspondence to: Dr. Joseph Romagnuolo, Digestive Diseases Centre, Gastroenterology and Hepatology, Medical University of South Carolina, 96 Jonathan Lucas St., Ste. 210, PO Box 250327, Charleston SC 29425; fax 843 792-8395; romagnuo@musc.edu 